\title{
Corrigendum
}

\section{Pharmacogenetic prediction of clinical outcome in advanced colorectal cancer patients receiving oxaliplatin/5-fluorouracil as first-line chemotherapy}

L Paré, E Marcuello, A Altés, E del Río, L Sedano, J Salazar, A Cortés, A Barnadas and M Baiget

British Journal of Cancer (2009) 100, 1368. doi:I0.1038/sj.bjc.6605004 www.bjcancer.com

(C) 2009 Cancer Research UK

Correction to: British Journal of Cancer (2008) 99, 1050-1055. doi: $10.1038 /$ sj.bjc. 6604671

Upon publication of the above manuscript in Volume 99 of $B J C$ the authors noted a small error in the affiliations of L Paré, E del Rio, A Cortés and M Baiget. The full affiliations (addition in bold) is now shown below.

L Paré ${ }^{1}$ E Marcuello ${ }^{2}$, A Altés ${ }^{3}$, E del Río M $^{1,4}$, L Sedano ${ }^{4}$, J Salazar $^{4}$, A Cortés ${ }^{1}$, A Barnadas ${ }^{2}$ and M Baiget ${ }^{1,4}$
${ }^{1}$ Department of Genetics, Hospital de la Santa Creu i Sant Pau, Universitat Autonoma de Barcelona, Barcelona 08025, Spain; ${ }^{2}$ Department of Clinical Oncology, Hospital de la Santa Creu i Sant Pau, Barcelona 08025, Spain; ${ }^{3}$ Department of Hematology, Fundació Althaia, Manresa, Spain; ${ }^{4}$ Center for Biomedical Research on Rare Diseases (CIBERER), Barcelona 08025, Spain 